\title{
Alteraciones desde el antimundo. La mosca de George Langelaan y David Cronenberg
}

\section{Alterations From the Anti-World. The Fly by George Langelaan and David Cronenberg}

\author{
Antonio Míguez Santa CruZ \\ Universidad de Córdoba \\ gesto_tecnico@hotmail.com \\ ORCID ID: 0000-0001-7610-561
}

\begin{abstract}
Resumen: Muchos fans del terror cinematográfico consideran $\mathrm{La}$ mosca (1986) como la película más influyente dentro de la filmografía de David Cronenberg. Sin embargo, el guion fue adaptado a partir de un cuento escrito por el periodista George Langelaan en 1957, esencialmente distinto en forma y fondo al relato fílmico. Nuestra intención en este artículo será explicar los porqués de estas alteraciones, sobre todo apoyándonos en la compleja figura del adaptador: David Cronenberg. De este modo iniciaremos un periplo hacia las principales inquietudes artísticas del creador canadiense, para quien el hombre posmoderno, en su ansia por alcanzar la evolución perfecta, podría verse abocado tanto a la destrucción de su espíritu como a la deformación de su cuerpo.
\end{abstract}

Palabras clave: Adaptación cinematográfica, George Langelaan, David Cronenberg, Nueva Carne, Tecnología, Horror corporal.

\begin{abstract}
Many fans of cinematic terror consider The Fly (1986) as the most influential film in David Cronenberg's filmography. However, the script was adapted from a story written by journalist George Langelaan in 1957, essentially different in form and substance from the film story. Our intention in this article will be to explain the reasons for these alterations, especially relying on the complex figure of the adapter: David Cronenberg. In this way we will begin a journey towards the main artistic concerns of the Canadian creator, for whom postmodern man, in his desire to achieve perfect evolution, could be doomed both to the destruction of his spirit and the deformation of his body.
\end{abstract}

Key Words: Film adaptation, George Langelaan, David Cronenberg, New Flesh, Technology, Body Horror. 


\section{LANGELAAN Y SU MOSCA}

De padre británico y madre francesa, George Langelaan (1908-1972) desempeñó una valiosa labor como periodista durante los prolegómenos de la II Guerra Mundial. Ya en pleno conflicto y debido a sus profundas convicciones antifascistas, decidió participar activamente ejerciendo como espía de los Aliados en la Francia ocupada. No demasiado tiempo después sería capturado y condenado a muerte por los nazis, aunque tuvo la suerte de escapar a tiempo para participar en el desembarco de Normandía (Carrol, 2015: 331). A partir de los años cincuenta comenzó a publicar diversos relatos en la revista masculina Playboy, destacando muy por encima del resto La Mosca, que vio la luz allá por 1957.

En él se aborda la historia del científico Robert Browning, quien, subvencionado por el Ministerio del Aire, efectúa varios experimentos de teletransportación bajo el más estricto de los secretos. A lo largo del proceso, Browning aprecia leves alteraciones en los elementos teletransportados, como la triste desintegración del gato de la familia, Dandelo, entre otros contratiempos. Cuando por fin consigue revertir tales problemas, emprende la prueba de fuego consigo mismo, no reparando en el detalle de que, en el último instante, se introduce una mosca en la cabina. Al aparecer recompuesto en el habitáculo de recepción, observa con horror cómo su cabeza y uno de sus brazos muta hasta ser como los de un insecto. La mosca con la que intercambió partes de su anatomía escapa, motivo por el que es incapaz de retornar a su forma humana. Ante esas circunstancias, Browning no vacila en destruir su máquina, para a continuación implorarle a su esposa, Anne, que lo mate usando una prensa hidráulica de la fábrica de su hermano, Arthur. Una vez satisfecha la última voluntad de su marido, Anne exige a su cuñado que contacte con la policía para hacerla responsable de la muerte de su esposo. Sin pruebas que contradijeran su testimonio la mujer es recluida en un centro psiquiátrico, donde decide escribir la verdadera historia de lo ocurrido con el objetivo de que se supiera en su debido momento. Semanas más tarde, cuando Arthur acaba de leer el asombroso manuscrito, es informado de que su autora acababa de suicidarse en el hospital. Tras avisar al inspector Twinker y entregarle el documento, le confiesa que aquella misma mañana había aplastado a una mosca de extraña cabeza blanca que estaba a punto de ser devorada por una araña.

El éxito del relato fue tan rotundo que ese mismo año la productora 20th Century Fox adquirió los derechos para llevar la historia al cine. El filme vio la luz en junio del año siguiente, con Al Hedison, Patricia Owens y el célebre Vincent Price entre el elenco protagonista. Según los parámetros que la revista Trasvases entre la literatura y el cine propugna subvertir, hablaríamos de una adaptación estupenda en función de su casi reverencial "fidelidad" al texto matriz. Pero ya sabemos que la semejanza con el original ni mucho menos es sinónimo de calidad o tan siquiera una 
virtud objetiva, sobre todo cuando algunas de las ingenuas imágenes de la cinta no han soportado de la mejor forma el paso del tiempo.

Y decíamos casi porque en el filme se dan un par de novedades respecto al hipertexto. La primera corresponde al amor frustrado de Arthur por su cuñada, en un recurso cuyo único objetivo era cumplir con los clichés propios del cine de los años cincuenta. Quizá más importante aún sea la crítica hacia la ultra-tecnología, apreciable principalmente en la conversación posterior a la desaparición de Dandelo:

HÉlÈnE Delambre: André, prométeme una cosa. Que no harás más experimentos con animales.

ANDré Delambre: Te lo prometo. No haré más experimentos con animales.

$\mathrm{H}$ : Creo que estás jugando a ser Dios

A: Dios nos dio la inteligencia para que descubriéramos las maravillas de la naturaleza. Sin esa inteligencia no podríamos hacer nada.

$\mathrm{H}$ : André, a veces... me da miedo. Hay tanto avance en nuestra época: la electrónica, los cohetes, los satélites, velocidades supersónicas y ahora esto...

A: Pero en cambio no te asusta ni la $\mathrm{TV}$, ni los rayos $\mathrm{X}$ ni la electricidad, ni el hecho de que la tierra sea redonda.

$\mathrm{H}$ : No... pero es que todo va tan deprisa... No puedo asimilar el progreso. Es tan rápido...

El subtexto tecnofóbico no dejaba de ser el fiel reflejo de aquella sociedad inquieta, que habitaba en un mundo donde la carrera tecnológica constituía el único elemento disuasorio de una hipotética guerra. No obstante, aquí disponemos de un inesperado nexo con la reescritura de Cronenberg, como el lector podrá comprobar en los epígrafes 5 y 6 .

\section{2. ¿UN REMAKE EN 1986?}

A mediados de los ochenta Charles Edward Pogue buscaba relanzar su hasta entonces discreta carrera como creador de historias. Después de todo, aquel semidesconocido guionista solo había firmado algunos trabajos para TV y su carrera no terminaba de apuntar a un lugar fijo. Pocos meses después Pogue conocería al mánager Kip Ohman, quien le puso sobre la mesa un proyecto distinto a los anteriores llamado La mosca. El escritor de Cincinnati se interesó por él desde un principio porque pensaba que podía extraer más partido a la historia que James Clavell en 1958, aunque para ello hubiera de cambiar varios conceptos de base. En esa dirección se fichó como director de la futura cinta a David Cronenberg, libre tras romper un acuerdo con Dino de Laurentis para rodar Desafío total (Total Recall, 1990). Con el torontoniano llegaría la totalidad de su equipo de producción, entre los que destacaba el especialista en efectos especiales Chris Walas, que tan buenos resultados dio en Scanners unos años antes. Cronenberg, no obstante, se mostró renuente a rodar un simple remake de la producción de 1958 , por lo que puso como condición ineludible revisar el guion de 
Pogue y así reinterpretar a su gusto el texto original de Langelaan. Para ello introdujo escenas con trucos visuales nunca vistos hasta aquel entonces, conocedor de hasta qué punto su amigo íntimo, Chris, podría aportar en lo que mejor sabía hacer: crear fantasías visuales.

Como era habitual en la carrera de Cronenberg, el equipo se trasladó hasta las afueras de Toronto, donde alquilaron una nave y recrearon el set que serviría de laboratorio a Seth Brundle, el personaje protagonista que sustituiría al Robert Browning del original de Langelaan. Para interpretarlo se fichó a Jeff Goldblum, que con el paso del tiempo demostraría lo bien que le sentaba meterse en la piel de académicos, a juzgar por el carisma alcanzado por el Dr. Ian Malcom en Jurassic Park (Steven Spielberg, 1993). En esta ocasión el actor se sumergió hasta tal punto en el rol de Seth Brundle que seguía actuando incluso después de que la cámara dejara de grabar, lo cual acabó por generar cierta incomodidad en algunos compañeros de rodaje. De una forma u otra, lo que sí resultaba evidente era la voluntad de productores, guionistas, director y actores, de instituir un producto esencialmente genuino, con carácter propio y que poca o ninguna relación tuviera con el relato corto de 1957.

\section{DAVID CRONENBERG}

Nacido en Ontario en 1943, fruto de la relación entre un periodista y una musicóloga, el pequeño David creció en un entorno muy propicio para el desarrollo intelectual y el estímulo cultural. Tal vez por ello gustaba de escribir cuentos en los que empezó a desplegar la compleja sensibilidad que llevaba en su interior. Así, influenciado en sus inicios por la literatura en mayor medida que por el cine, Cronenberg sobresalió años más tarde por poseer un estilo propio, en el cual destacaba el constante trasluz psicológico de personajes situados en situaciones extrañas y poco habituales. Rasgos como el anterior definen a nuestro hombre como una rara avis en el seno de la industria cinematográfica americana.

$\mathrm{Su}$ infancia se vería profundamente marcada por dos aspectos que influirían decisivamente en su ulterior filmografía: el retraimiento y la espantosa enfermedad degenerativa sufrida por su padre, Milton Cronenberg. Ya en 1963 ingresa en la Facultad de Medicina de Toronto, pero nunca se vería realizado espiritualmente hasta que se matriculó en literatura inglesa. Allí conoció a David Sector, quien le introducirá en el mundo del cine, además de ayudarle a descubrir un nuevo medio para transmitir sus inquietudes. Después de rodar un par de cortos, Cronenberg comenzó su carrera cinematográfica profesional con Vinieron de dentro de..., a la que siguieron singulares reinterpretaciones de los géneros de terror y ficción de ciencia, tales como Cromosoma 3, Scanners o La Mosca. En todos estos trabajos se abordan temáticas como la concupiscencia, la enfermedad o la autodestrucción, que pasarían a ser estilemas esenciales en la obra del cineasta canadiense. 
Aunque si algo destaca en la carrera de David Cronenberg es el notable cambio de paradigma visto en su filmografía a partir de Una historia de violencia (2005). Desde ese momento, el creador abandonó los paisajes propios del horror y la sci-fi para abrazar temáticas más realistas, en las que la estilización visual, el gran presupuesto o la participación de estrellas consagradas dispersaron el delicioso buqué a serie B tan característico del primer Cronenberg. No es baladí subrayar este punto, máxime cuando no conocemos a otro cineasta cuya obra se haya dividido de manera tan evidente, pero al mismo tiempo sea tan reconocible en todo su conjunto.

\section{Cronenberg y SU Mosca}

La particular reescritura de Cronenberg da comienzo con el excéntrico científico Seth Brundle conociendo a Veronica Quaife, una periodista especializada en ciencias, en el contexto de un congreso académico. Después de flirtear con ella, consigue convencerla de que lo acompañe a su laboratorio, con la excusa de mostrarle un invento revolucionario. Se trata de un par de cabinas llamadas telepods que presuntamente posibilitan la teletransportación de cualquier materia entre una y otra. Brundle convence a Veronica para que mantenga en secreto su creación por el momento, a cambio de cederle la futura exclusiva. Apenas unos días más tarde, Seth y Veronica comienzan una relación. Su primer encuentro sexual llevó al físico a reprogramar el telepod con el objetivo de teletransportar tejidos vivos, tras un desastroso primer intento usando a un babuino. Una vez Brundle realizó los ajustes pertinentes, pudo realizar con éxito el ensayo empleando en el proceso al hermano del malogrado simio. La consecuente euforia de su triunfo lo llevaría a introducirse él mismo en la cabina, inconsciente de que una mosca también se hallaba dentro del telepod. A pesar de ello, Brundle no solo emergería de la segunda cabina sin ningún tipo de anomalía aparente, sino que además manifestaría una energía y potencia sexual antinaturales, que achacaría a una eventual purificación de su cuerpo.

El escenario pronto dio un giro de ciento ochenta grados, pues Seth comenzó a necesitar una ingesta masiva de azúcar al tiempo que se convirtió en alguien cada vez más violento y arrogante. Parecía estar obsesionado con los supuestos beneficios de teletransportarse, del mismo modo que un drogadicto fantasea con consumir su próxima dosis. Justo después de que el protagonista intentase infructuosamente convencer a Veronica de experimentar el proceso, observó cómo sus uñas empezaban a desprenderse de la piel, lo cual lo llevó a elucubrar que algo salió mal durante el proceso de teletransportación. Al revisar los registros almacenados en su ordenador, Brundle descubrió que la interfaz de telepod colapsó debido a la presencia de dos formas de vida distintas en la misma cabina transmisora, de modo que el algoritmo resolvió la paradoja uniendo a nivel genético-molecular ambos seres en uno solo. La criatura resultante 
comenzó un proceso de deterioro imparable, perdiendo diversas partes del cuerpo y mutando hasta llegar a ser algo grotesco.

Aún en su deformidad, Seth volvió a contactar con su examante, Veronica, para confesarle que estaba transformándose en "Brundlemosca", un híbrido entre humano e insecto capaz de vomitar enzimas digestivas o caminar por paredes y techos. Lo más preocupante, pese a todo, fue el hecho de reconocer que se hallaba en un proceso de pérdida de la razón y compasión humanas, impulsado por una explosión de instintos primitivos que ahora afloraban y que de ninguna manera podía controlar. El único e hipotético remedio consistía en instalar un programa de fusión en la computadora del telepod, con el objetivo de diluir los genes de insecto de su cuerpo en una mayor cantidad de ADN humano.

Mientras tanto, Veronica advirtió estar embarazada de Brundle, lo cual le ocasionaría una serie de terribles pesadillas, como aquella en que da a luz una larva gigante. Asustada, le rogó a su jefe Stathis que la acompañase a una clínica de aborto en plena madrugada. En medio de la operación, Brundle irrumpió en la sala derribando la pared de un golpe para secuestrar a Veronica antes de que el aborto fuera efectivo. El mutante pensaba usar los telepods para fusionarse con ella y su hijo no nato en una sola entidad. Justo cuando arrastraba a la mujer dentro de una de las cabinas, esta propinó una patada directa a la mandíbula del monstruo, que, tras desprendérsele del cráneo, dejó a la vista una aberrante criatura humano-insectoide. Stathis, mortalmente herido por haber sido rociado con el corrosivo vómito de la criatura, disparó una escopeta contra los cables que conectaban el telepod de Veronica a la computadora principal. Intentando escapar de su propia cabina justo cuando el proceso de fusión finalizó, Brundle-mosca fue grotescamente fusionado con el metal y el cableado del segundo telepod. El engendro reptante acercó su cabeza al cañón del arma sujetada por Veronica, que, sin apenas vacilar, apretó el gatillo.

\section{LA NUEVA CARNE}

Desde el comienzo del proyecto hemos visto cómo David Cronenberg quiso desmarcarse del filme de Kurt Neumann añadiéndole elementos absolutamente personales. Quizá el cambio fundamental radicara en el hecho de que el científico no acabase convirtiéndose en un insecto, sino que fuese transformándose, poco a poco, en un híbrido entre mosca y humano. Probablemente tengamos aquí una de las influencias de la traumática enfermedad sufrida por Milton Cronenberg en el cine de su hijo, pues en ninguno de sus otros trabajos la degeneración del cuerpo y la mente adquieren una relevancia narrativa tan alta.

En este caso la aparición de unas cerdas en la espalda del protagonista supuso el inicio de su descenso a los infiernos, ya que poco después descubrió que pertenecían a una especie indeterminada de díptero. Hasta entonces, Cronenberg exploraba el conflicto a su manera -contemplativa e 
incluso pausadamente--, pero transcurrida la hora de metraje pone sus manos en el cuello del espectador, sometiéndolo a una sucesión de escenas perturbadoras en las que el body horror y el gore adquieren un total protagonismo. De cualquier forma, hemos de advertir al lector de que dicha explicitud visual nunca implica que Cronenberg deje de aproximarse elegantemente a la tragedia, constituyendo un ejemplo de cómo mediante una adecuada dirección se pueden combinar perfectamente terror y drama.

Por consiguiente, la cinta evidencia lo que el mismo director denominaría nueva carne, o la génesis de un cambio en el seno del individuo que se manifiesta a través de caprichosas alteraciones en el cuerpo (Navarro, 1992: 50). Hablamos de uno de los tótems de la filmografía de nuestro hombre, una marca de agua reconocible que persigue mostrar la paulatina suplantación de lo natural por medio de lo artificial. En otras palabras, Cronenberg busca presentar la realidad paralela del individuo contemporáneo, aquella fundada en torno a cualquier necesidad presuntamente solucionada por el avance tecnológico. Sirva como paradigma la kafkiana historia de Brundle, quien tras desear simplemente el bien común observa cómo su cuerpo se va transformando en algo repugnante. La metáfora, semejante en cierto modo a la mostrada por Shinya Tsukamoto dos años después en Tetsuo, el hombre de Hierro, advierte sobre los riesgos que implica la tecnología innecesaria o mal aplicada (Palacios, 2013: 33). Y es que Brundle, si bien sorprendido ante su nueva situación, acaba no solo asimilándola, sino también embriagado por la posibilidad de ser consumido por ella.

La idea básica de una mente que trasciende a otro nivel inalcanzable para el cuerpo ya se explotó en Cromosoma 3 mediante unas horrorosas erupciones que afloraban cuando el individuo se estresaba. En palabras del mismo Cronenberg, recogidas en la edición española de aquel DVD, «hablamos de un cáncer creativo. Algo que normalmente verías como enfermedad ahora se va a otro nivel de creatividad y empieza a esculpir dentro de tu propio cuerpo». Probablemente el mejor exponente de esta filosofía se dé en Videodrome (1983), cuyo protagonista, Max Renn, emprende una odisea bizarre en la que el desarrollo tecnológico y la deshumanización de la sociedad diluyen los límites entre cuerpo y mente, sueño y realidad. Solo hemos de sustituir la máquina teletransportadora por la televisión y su influjo, de poder subyugante y manipulador.

\section{THE MAD DOCTOR}

El científico loco es un arquetipo narrativo común dentro de la ficción de ciencia. Por lo general, hablamos de un investigador superlativo que pone su capacidad al servicio de empresas éticamente cuestionables. Y es que, al igual que el vampiro, el zombie o el hombre lobo, el mad scientific provoca terror, mas lo ejerce al transitar por esa fina línea entre la genialidad y la locura, poniendo su intelecto superior al servicio de fines abyectos. Lo 
habitual en este tipo de personajes sería su inmersión en una vorágine de deseo, donde el afán de conocimiento o el dominio sobre su entorno actúan como motores principales de la acción. De cualquier modo, y a pesar de que pocos estudios se hayan preocupado en delimitarlo, existen varios matices dentro del concepto. Desde nuestra perspectiva, el mad doctor debería seguir sintiéndose embriagado por su creación incluso cuando esta haya manifestado su naturaleza aviesa o perjudicial. Por ejemplo, si el lector piensa en un mad doctor, quizá el Dr. Victor Frankenstein irrumpa en su mente antes que cualquier otro, aunque nosotros pensamos que dejaría de permanecer en esa lista en el momento en que se arrepintiera de su creación o bien intentase destruirla. Por el contrario, el trasunto de Frankenstein creado por Lovecraft, Herbest West, persiste en su fanatismo aun después de evidenciar la peligrosidad de sus investigaciones, en un desarrollo imparable que lo llevará a ser destruido por sus propias criaturas, además de confirmarlo como un mad doctor en toda regla.

Tanto el relato de Langelaan como la reescritura de Cronenberg presentan mad doctors semejantes en su premisa original, pero a la postre opuestos en su desarrollo. En un primer momento, ambos comparten la voluntad de llevar a cabo sus experimentos en aras del bien común, pero una vez se producen las respectivas mutaciones se abre el abismo narrativo entre hipertexto e hipotexto. Mientras Langelaan describe a un hombre desesperado ante las repercusiones de su metamorfosis, Cronenberg pone en escena a un científico eufórico por su recién adquirida fuerza física, casi orgulloso de haber podido evolucionar, en suma, a una nueva carne (Higueras, 2016: 25).

\section{SCIENCE HORROR}

La ficción de ciencia y el terror han recorrido un periplo en común desde el principio. De hecho, justo en la página anterior hablábamos de Frankenstein, protagonista de la primera novela sci-fi en la historia de la literatura, a pesar de que sea considerada popularmente el relato de terror por excelencia, junto a Drácula. Conque ¿dónde se hallaría el límite entre un género y otro? Desde luego, la frontera puede llegar a ser extremadamente difusa, cuando no desaparece por completo. A esos textos en los que convergen matices de una y otra tipología hemos convenido en llamarlos Science Horror, u Horror de Ciencia, con el objetivo de diferenciarlos del resto. Ejemplos evidentes de la literatura serían el ya citado Moderno Prometeo de la extraordinaria Mary Shelley o la mayor parte de la obra de H.P. Lovecraft, mientras que en el cine podríamos nombrar Alien, el octavo pasajero (Ridley Scott, 1979), Horizonte final (Paul W.S. Anderson, 1997) o la recentísima serie Stranger Things (Duffer Bros, 2016).

Hemos querido traer a colación este término precisamente porque Cronenberg incorporaría al aparato tecnológico de Langeelan un ostensible 
repertorio de mecanismos narrativos propios del terror (Sala, 2003: 75), elevándolos hasta territorios inexplorados, mas con el cuerpo del hombre y las distorsiones de su mente situados como pilares centrales del espanto. En efecto, a lo largo del filme de 1986 asistimos a una gran sucesión de escenas concretamente terroríficas, más cercanas a la narrativa gótica del $\mathrm{s}$. XIX que al thriller de ciencia ficción, rayano con la novela negra, que era el relato de 1957. Sustituyamos, por ejemplo, el típico castillo veteado por jirones de niebla por el laboratorio de Brundle; disponemos, además, del escenario sobrenatural -según Todorov (2003), la sci-fi difícilmente dejaría de estar incluida en este ámbito- idóneo a la hora de suscitar reconcomios en torno al misterio y el miedo; y por supuesto, hacen acto de aparición las emociones desbocadas, acompañadas del erotismo o la sexualización de los personajes.

Punto y aparte supone la explotación del body horror, acaso el rasgo más reconocible de todo el filme. En este sentido, destaca una de las escenas descartadas del montaje final. En ella, un Brundle absolutamente desfigurado pretende fusionar a un simio y un gato, movido por su ego y vanidad sin límites. El resultado es una abominación aullante de dos cabezas, a la que su creador apalea hasta la muerte empleando una barra de acero. Aquí podemos observar el uso del horror corporal a tres niveles distintos. El primero corresponde a la consabida desfiguración del protagonista, desagradable para el espectador por encarnar la desvirtuación del sacralizado cuerpo humano; el segundo concierne al horror resultante del experimento, a cuya fealdad le habríamos de sumar la agonía sufrida por los animales; y el tercero, seguramente el más convencional, estaría relacionado con la violencia hacia aquella aberrante criatura, viva, al fin y al cabo, y machacada a base de golpes. Deformidad doblemente deformada.

A continuación, Brundle-mosca, poseído por la frustración y el frenesí, se evacuó por la ventana quedando encaramado a la pared en medio de una noche tormentosa. De súbito, la cámara se desliza hacia el costado de la criatura, que empieza a bombear de forma rítmica, para finalmente desgarrar la piel y dejar ver una pata retorcida, similar a la de un cangrejo. El propio protagonista decidió extirpársela al instante, dejando una llaga muy parecida a la que Longinos infligiera a Cristo. De haber sido así, la historia trascendería la calamidad individual para llegar a ser un drama apocalíptico, en el cual Brundle-mosca ejercería de mesías, engendrando sin cesar hijos-larva capaces de desplazar a los humanos de la cima evolutiva.

Como decíamos, el corte anterior no se incluyó en la película porque David Cronenberg dedujo que el espectador perdería la empatía hacia Brundle después de su excesiva demostración de crueldad y, sobre todo, por protagonizar un hecho de hipotéticas relecturas religiosas. De una forma u otra, es evidente cómo el texto matriz se desarrollaba dentro de los márgenes de la ficción de ciencia, mientras que Cronenberg insufló sus 
inquietudes a la película de 1986, casi todas relacionadas con el terror, transformándola por completo.

\section{EL ELLO}

El psicoanálisis de Sigmund Freud proponía que la personalidad del individuo se explicaba en base a las relaciones entre las distintas entidades de nuestra psique: el ello, el yo y el superyó (1980). Como el lector conocerá sobradamente, el ello corresponde al espíritu primitivo de nuestro cerebro, aquel encargado de expresar las necesidades más brutales y animales, como alimentarse, agredir o fornicar. Por tanto, también representa el ansia por el placer instantáneo sin considerar las consecuencias sociales o el juicio moral. Freud pensaba que la mayoría de seres sociales intentaban reprimir esos instintos para encajar mejor en la sociedad, creando una suerte de estructura artificial que las sometiera: el superyó. Aquí se reflejarían las normas éticas, morales y religiosas de una sociedad dada, transmitidas, la mayoría de las veces inconscientemente, por familia, profesores, medios de comunicación, etc. El superyó también es el estadio mental que nos hace sentir culpables cuando mentimos o pensamos algo "inapropiado". El pleito interno mantenido entre el ello y el superyó da lugar al yo, es decir, el justo punto medio de lo que la sociedad espera de nosotros y lo que realmente deseamos. En este sentido, el yo intentará satisfacer en la medida de lo posible las prístinas necesidades del ello, si bien dentro de los márgenes socialmente aceptados por el superyó.

El relato de la mosca, tanto en su vertiente literaria como en la fílmica, muestra directamente la paulatina pérdida del ser social y el aumento de los instintos animales. Al fin y al cabo, la idea posee todo el sentido del mundo, máxime cuando los genes del protagonista se mezclan con una de las formas de vida más simples de la naturaleza: el insecto. El factor relevante es cómo aborda la conciencia humana, en cada caso, la preeminencia de lo animalístico frente a la humanidad artificial. En el caso de Langelaan, el Dr. Robert Browning llega a dominar desde el principio a la bestia, llegando incluso a la autoinmolación con el fin de evitar el mal al resto de sus congéneres. La cuestión daría un giro de tuerca en el filme de Kurt Neumann (1958), cuando el brazo monstruoso de André Delambre intentaba agarrar a Helene como si tuviera voluntad propia. Esto nos llevaría a pensar mayormente en la coexistencia de dos personalidades dentro de un mismo individuo que en una psique poliédrica, donde los estratos más profundos van imponiéndose a los superiores. El Seth Brundle imaginado por Cronenberg configura exactamente esa idea: un instinto abierto al caos y emancipado, por fin, de las cadenas éticamente recomendables. En una de las últimas conversaciones mantenidas entre Seth y Veronica, él le pregunta a modo de chanza si conoce «la política de los insectos». Ella contesta que no, a lo que el mutante, ya casi en toda su deformidad, afirma: «yo tampoco... los insectos no tienen política. Son 
brutales... no tienen compasión ni compromiso. No se puede confiar en un insecto».

La anterior línea de guion no dejaba de ser una última advertencia emitida por la humanidad residual que aún habitaba en Seth. Poco más tarde, al emerger del telepod, se desbordó su desmedido apetito sexual; abandonó los códigos de conducta y formalidad propios de la humanidad, a juzgar por el lamentable estado de su apartamento; incrementó la violencia hasta un grado desmedido, sobre todo focalizada en sus rivales sexuales, a saber, Stathis Borens; y, por último, desarrolló un ansia irrefrenable por la perpetuación de su especie, en función de su entusiasmo al conocer que Veronica se hallaba encinta.

\section{CODA}

Suele considerarse La mosca de David Cronenberg un remake de la cinta de 1958. De tal modo aparece, por ejemplo, en Filmaffinity, entre otras webs de votación ${ }^{1}$. El inconveniente reside en que ni Charles Edward Pogue ni el cineasta canadiense tomaron como base el trabajo de Kurt Neumann, sino que acudieron directamente al relato de George Langelaan. De modo que deberíamos evitar hablar de remake porque aquí se creó un producto prácticamente desde cero, en gran medida debido al interés artístico de Cronenberg por la violencia, el sexo, la degeneración o la enfermedad, así como por la decisión de explotar el aspecto dionisiaco del personaje principal.

La mosca permanece en la memoria de los fans del horror de ciencia como una de las mejores películas del género, llegando a ser clave en diversos aspectos narrativos para el muy posterior cine de supers tan explotado en el s. XXI. Pero por encima de todo, demostró que un guion puede llegar a asumir un peso específico tan relevante como para imponerse sobre la obra literaria original. Resulta paradójico que Cronenberg jugara con dos elementos distintos en forma y fondo - el texto de Langelaan y sus propias ideas-, mezclándolos con la misma clase de ciencia que había usurpado el cuerpo de Seth Brundle. En consecuencia, fue indudable el acierto de los productores al apostar por un creador más allá de las estructuras preestablecidas, y que, aún hoy, a pesar de lo mucho que ha evolucionado la apariencia de su cine, sigue poniendo en tela de juicio la moral del hombre situado en un universo posmoderno.

\section{BibliografíA CITADA}

CARrol, Jordan (2015), «Reading Playboy for the Science Fiction.

Reading Playboy for the Science Fiction», American literature: A journal of literary history, criticism and bibliography, 87/2, págs. 331-358.

\footnotetext{
${ }^{1}$ https://www.filmaffinity.com/es/film353875.html (fecha de consulta: 10/05/2020).
} 
Freud, Sigmund (1980), Obras Completas. XXIII. Moisés y la religión monoteista. Esquema del psicoanálisis y otras obras (1937-1939), Buenos Aires, Amorrortu.

Higueras, Rubén (2016), Mad doctors. El sueño de la razón, Madrid, T\&B.

Navarro, Antonio José (1992), «David Cronenberg: los secretos de la Nueva Carne», Dirigido por, 203, págs. 50-70.

Palacios, Jesús (2013), «Extremos orientales», en A. Sala (coord.), Takashi Miike. La provocación que llegó de oriente, Madrid, Calamar, págs. 33-43.

SALA, Ángel (2003), «Manifestaciones semánticas de lo siniestro en Cronenberg y otros profetas de La Nueva Carne», en C. Lozano (coord.), Lo siniestro: III Curso de Cine y Literatura, Burgos, Universidad, págs. 75-90.

TODOROv, Tzvetan (2003), Introducción a la literatura fantástica, México D.F., Coyoacán.

Fecha de recepción: 18/05/2020.

Fecha de aceptación: 25/07/2020. 